\title{
TENDÊNCIAS NAS PESQUISAS GEOGRÁFICAS SOBRE CIDADES PEQUENAS NO BRASIL: APONTAMENTOS PARA ANÁLISE
}

\author{
ORLANDO MOREIRA JUNIOR ${ }^{1}$ \\ Universidade Estadual Paulista Júlio de Mesquita Filho - Rio Claro
}

\section{Introdução}

$\mathrm{O}$ argumento principal deste trabalho envolve uma reflexão sobre a cidade pequena e o urbano, sua trajetória na ciência geográfica brasileira, seus dilemas atuais e sua tendência analítica. Portanto, o presente artigo traz as cidades pequenas para o centro do debate no âmbito da Geografia, porém com subsídios para se pensar o vislumbrar do urbano, que deve ser de interesse também do Urbanismo, do Planejamento e das Ciências Sociais como um todo.

Com esse propósito, foi realizado um levantamento nos principais programas de pós-graduação em Geografia do Brasil para, num primeiro momento, quantificar e depois qualificar as pesquisas que foram desenvolvidas sobre o tema das cidades pequenas. Nesta direção, a proposta do levantamento do que tem sido produzido na área geográfica no Brasil - tendo por base pesquisas acadêmicas de Mestrado e Doutorado permite observar o modo como se têm desenrolado as discussões sobre o tema, os conceitos que são abordados, os recortes espaciais e os referenciais empíricos envolvidos em contextos ou regiões diferenciadas.

${ }^{1}$ Doutorando em Geografia pelo IGCE-UNESP - Rio Claro quando da redação do presente trabalho. Contato: orlandomoreirajunior@yahoo.com.br. 
De um lado, isso ajuda a evidenciar os variados olhares sobre as cidades pequenas no que diz respeito às bases lógicas da investigação científica. E, por outro lado, reconhecer esses fundamentos e teorias acerca da natureza do espaço urbano em cidades pequenas permite promover uma visão crítica, ao mesmo tempo em que proporciona uma reflexão dos principais problemas que nelas se manifestam.

\section{A diversidade urbana e as cidades pequenas no Brasil}

Quando pensamos nas cidades brasileiras, deparamo-nos com grandes diferenças regionais. Isso é normal em um país com dimensões continentais. Assim, ao considerar a urbanização brasileira, deve-se respeitar a heterogeneidade nacional e as especificidades regionais e locais. Ademais, cidades de diferentes dimensões territoriais assumem formas, funções e estruturas singulares nas diferentes porções do território brasileiro, desempenham papéis distintos na rede urbana, bem como estabelecem diferentes níveis de interdependência entre si e em relação ao campo.

Pensar a diversidade urbana brasileira requer uma reflexão a partir dos processos mais recentes da economia e da urbanização por meio das quais é possível verificar a constituição da rede urbana pautada na competição entre as cidades. De fato, a urbanização brasileira é em sua essência um fenômeno recente, ao passo que o país em si goza de uma história recente, sendo possível identificar, grosso modo, dois períodos para explicar a evolução da urbanização no país: o primeiro, anterior às décadas de 1940-1950 e o segundo, pós 1940-1950.

No período anterior às décadas de 1940-1950 a economia agroexportadora explica a reduzida importância das cidades no Brasil, cujos papéis eram predominantemente políticos e administrativos. Conforme Santos (1994), no começo a cidade era bem mais uma emanação do poder longínquo, uma vontade de marcar presença num país distante a fim de estabelecer uma ponta de rede do poder colonial para explorar o território, num primeiro momento através da extração e, depois, pela agricultura. O país era composto por subespaços organizados por lógicas próprias ditadas, sobretudo, pelas relações com o mundo exterior. 
A partir de 1940 os nexos econômicos tornam-se mais importantes e passam a comandar a urbanização. As transformações econômicas resultaram numa série de mudanças socioespaciais. Até meados do século passado o Brasil era um país eminentemente rural. Seu processo de urbanização deu-se praticamente no século XX, ligado ao processo de industrialização. Ou seja, o país que até a década de 1940 era caracterizado por uma economia agroexportadora começa a ganhar características de um país urbano-industrial. A urbanização que acompanhou a industrialização do país arregimentou enorme contingente de pessoas, num processo quase contínuo de crescimento da área urbana das cidades, graças ao aumento das migrações internas e externas.

A alta taxa de urbanização revela, de maneira diferenciada, um aumento contínuo e acelerado da população urbana, em comparação à diminuição da população rural. O censo de 2010 chegou a um resultado de $84 \%$ da população vivendo em áreas urbanas. No entanto, apesar desse valor elevado, dos 5.565 municípios existentes, 3.914 deles registram população inferior a 20 mil habitantes, e 1.043 possuem população entre 20 mil e 50 mil. Do total dos municípios, 4.957 apresentam população inferior a 50 mil habitantes, ou seja, aproximadamente $34 \%$ da população total do país. Enquanto isto, os 38 municípios mais populosos (com mais de 500 mil habitantes) abrigam cerca de $29 \%$ do total, como mostra o Quadro 1.

\begin{tabular}{|c|c|c|}
\hline Habitantes & Número de Municípios & Total da População \\
\hline Brasil & $\mathbf{5 . 5 6 5}$ & $\mathbf{1 9 0 . 7 5 5 . 7 9 9}$ \\
\hline Até 20.000 & 3.914 & 32.660 .247 \\
\hline De 20.001 até 50.000 & 1.043 & 31.344 .671 \\
\hline De 50.001 até 100.000 & 325 & 22.314 .204 \\
\hline De 100.001 até 500.000 & 245 & 48.565 .171 \\
\hline Mais de 500.000 & 38 & 55.871 .506 \\
\hline
\end{tabular}

Quadro 1: Municípios brasileiros por classe de tamanho da população, entre o período de 1970 e 2010.

Fonte: Censo Demográfico de 2010 - IBGE.

Organização: Orlando Moreira Junior, 2014. 
O quadro revela a amplitude da diversidade urbana brasileira. Mais do que reveladora do processo de crescimento demográfico, ela contribui para a explicação da distribuição da população entre cidades de diferentes tamanhos. Apresenta, ainda, o processo de concentração populacional em um número reduzido de grandes centros urbanos, ao mesmo tempo em que existe um número expressivo de cidades pequenas espalhadas por todas as porções do território.

O entendimento da cidade, no Brasil, deve voltar-se para a apreensão de três dimensões que nem sempre dialogam ou são convergentes entre si. A cidade como forma institucionalizada, a cidade enquanto conceito geográfico e a cidade real. Diante disto, refletir acerca das cidades e do urbano no Brasil suscita inúmeras indagações e, por conseguinte, diversas possibilidades de respostas. Entretanto, o primeiro ponto que consideramos elementar é admitir que só podem ser pensadas como resultado de processos que variam no tempo e no espaço. Logo, as cidades enquanto realidade material de um processo social mais amplo também deve ser assistida a partir de seu contexto temporal e espacial.

Com base nesses pressupostos, vale pensar os extremos que representam a diversidade urbana brasileira: o município mais populoso e o menos populoso são, respectivamente, São Paulo com 10.434.252 habitantes e Borá com seus 750 habitantes. Seria possível estabelecer uma comparação demográfica e espacial entre São Paulo e Borá? Ambas têm status de cidade mas apresentam uma imensa diferença demográfica, isto sem considerar as diferenças entre os papéis urbanos desempenhados por cada uma delas. De fato, essa é uma comparação injusta, contudo serve para nortear algumas discussões que se pretende destacar neste trabalho.

A primeira, é admitir que as cidades apresentam papéis urbanos e tamanhos demográficos distintos que se manifestam em diferentes graus de intensidade, existindo diferenças entre cidades de variados portes tal qual há entre cidades grandes. Se compararmos São Paulo com outras cidades como Rio de Janeiro, Salvador, Brasília, Curitiba, entre outras, vamos nos deparar com variações significativas também, tanto em aspectos quantitativos quanto qualitativos. Da mesma forma, se pensarmos a São Paulo de hoje vamos nos deparar com uma cidade diferente daquela do início do século ou mesmo das décadas de 1950 ou 1970, por exemplo.

Já no caso das cidades pequenas, podemos encontrar núcleos urbanos com menos de mil habitantes bem como cidades com mais de 50 mil, que 
adquirem características de cidades locais na rede urbana. Igualmente pode-se deparar com cidades com cerca de 50 mil habitantes que assumem características de uma cidade média, como são os casos de regiões com baixa densidade demográfica. Em termos práticos, isto significa que existem diversidades entre cidades pequenas do sudeste e do norte do país, por exemplo, assim como não são idênticas as cidades pequenas localizadas em áreas metropolitanas e aquelas que se encontram em áreas não metropolitanas; acrescenta-se a isso, diferenças entre as pequenas cidades antigas e as novas, o que é revelador de uma ampla multiplicidade de contextos.

Do ponto de vista institucional, no Brasil, o IBGE define as cidades pelo perímetro urbano das sedes municipais, sendo considerada urbana toda sede de município (cidade) e de distrito (vila), indiferente de suas características qualitativas ou quantitativas. Este critério envolve, de um lado, um questionamento científico por parte daqueles que estudam o espaço e, de outro, um caráter técnico que é o adotado pelos órgãos institucionais e pelos estados. Daí as discussões recorrentes sobre o caráter urbano das sedes dos 3.914 municípios brasileiros com população inferior a 20 mil pessoas (se acrescentar a população até 50 mil chega-se a 4.957, de um total de 5.565). Estes dados não têm importância somente pelos números em si, mas pelo que representam do ponto de vista políticoadministrativo, e por expor um grave problema: a questão da criação acelerada de municípios.

Sobre esse tema, duas considerações se sobressaem. A primeira diz respeito aos interesses econômicos e políticos. Ou seja, muitos processos de desmembramento têm se revelado como ações decorrentes de interesses político-eleitorais, ao invés de ter como motivação principal o crescimento populacional e econômico de determinado distrito, que demandaria maior autonomia. Daí a necessidade de um estudo prévio de viabilidade municipal como requisito ao processo emancipatório. Sob esse aspecto, sustenta-se a segunda consideração, pois como muitos municípios em todo o país são inviáveis em termos financeiros, suas receitas advêm, em grande parte, de transferências de recursos do estado (IPVA, ICMS, etc.) e, principalmente, da União, através do Fundo de Participação dos Municípios (FPM).

Do ponto de vista científico cidade pequena é um conceito de difícil elaboração. Deste modo, ainda se constitui um grande desafio estabelecer 
aprofundamento teórico-conceitual acerca dessas cidades, diferentemente do que tem sido desenvolvido para as cidades médias, por exemplo. No caso das cidades médias a discussão tem sido norteada não apenas por aspectos quantitativos, mas também pelas características qualitativas peculiares a esses núcleos urbanos. Os critérios para a definição conceitual são o caráter demográfico, a força de atração populacional, os fluxos com outros centros urbanos e a sua localização geográfica.

A localização desponta, portanto, como fator fundamental para traçar uma distinção entre cidades médias e as cidades de porte médio, ao passo que nem todas as cidades de porte médio desempenham papéis de cidades médias. O critério de classificação baseado no tamanho demográfico tem sido o mais utilizado para identificar as cidades médias, pelo menos como primeira aproximação. Entretanto, ao refletir a respeito do conceito de cidade média deve-se estar ciente de que é preciso incluir a estruturação interna de seus espaços, como suas relações com outras cidades - o que impõe o reconhecimento de seus papéis na estruturação urbana da rede (SPOSITO, 2004).

Da mesma forma poder-se-ia pensar as cidades pequenas, ou seja, além de se considerar o tamanho demográfico também há necessidade de procurar compreender os aspectos qualitativos e locacionais que influenciam nos papéis por elas desempenhados na estruturação da rede urbana. O tamanho demográfico ainda aparece como principal critério para a classificação do que seria uma cidade pequena. Ora utilizado como único aspecto para delimitar uma cidade pequena, ora empregado como um dentre outros fatores para tal definição, o tamanho demográfico é fundamental para o entendimento destas realidades urbanas. O Instituto Brasileiro de Geografia e Estatística (IBGE), por exemplo, estabelece, divulga e trabalha com classes de tamanhos de municípios.

Em geral as pequenas cidades se caracterizam por apresentar papéis urbanos pouco expressivos, com ausência de infraestrutura e serviços que proporcionem aos habitantes uma mínima condição de vida. São cidades que apresentaram intenso grau de dependência em relação a outras cidades no que tange aos serviços especializados de saúde, administração, entre outros ainda mais essenciais para a população menos ou nada abastada; ou seja, mais dependente dos serviços coletivos que a cidade deveria oferecer.

Nesse contexto se encontram a maioria dos pequenos núcleos urbanos. Compreendem-se, em sua ampla maioria, municípios 
extremamente pobres, parcos de recursos que possam suprir as demandas necessárias às mínimas atividades sociais e urbanas da população. A receita municipal advém, em grande parte, da transferência de recursos do estado e, principalmente, da União através do Fundo de Participação dos Municípios (FPM).

Daí a justificativa para se pensar as cidades pequenas no contexto brasileiro e ter os programas de pós-graduação em Geografia como referencial dessa análise. Afinal, cabe à Geografia analisar e compreender a organização do espaço, sendo um importante referencial para compreender o papel das cidades pequenas e seu espaço em discussão na ciência, ante a diversidade urbana do país.

\section{O estudo das cidades pequenas nos programas de pós-graduação em Geografia}

As Teses e Dissertações representam uma forma eficiente de comunicação do conhecimento e do desenvolvimento da ciência. Cooperam, especialmente, para o entendimento e à construção dos procedimentos metodológicos de diferentes recortes espaciais, em diferentes escolas de um país de dimensões continentais. Apesar de, na maioria das vezes, traçar um nexo com determinada localidade por meio de estudo de caso, essas fontes bibliográficas revelam tanto o resultado de um estudo quanto procedimentos que nos ensinam a pesquisar.

Assim, foi realizado um levantamento das Dissertações e Teses dos principais Programas de Pós-Graduação em Geografia das universidades públicas brasileiras. O período entre 2000 e 2010 foi o escolhido para tal análise, visto que representa não somente o período contemporâneo, mas, sobretudo, porque é o momento em que está em voga uma série de temáticas ou questões que envolvem o pensamento sobre as cidades, $\mathrm{o}$ planejamento e a gestão do espaço urbano e regional.

Foram selecionados os programas que possuem os cursos tanto de Mestrado quanto de Doutorado. Igualmente, procurou-se identificar a área de concentração do programa. É válido ressaltar a necessidade de considerar também o tempo de existência do curso, afinal, aqueles mais novos apresentam uma pequena produção acadêmica em comparação com 
escolas mais tradicionais que ditam ou ditaram o pensamento geográfico brasileiro.

Tal pesquisa foi efetuada com base na consulta ao Banco de Teses e Dissertações da CAPES, utilizando como critério a presença das expressões "cidade pequena", "pequena cidade", "cidade de pequeno porte" ou "cidade local" no título, nas palavras-chave ou sob ênfase nos resumos. A prioridade foi observar se o objetivo dos trabalhos tinha como objeto de estudo as cidades pequenas. Todavia, apesar do olhar atento e minucioso, não se descarta a possibilidade ter havido uma omissão involuntária de pesquisas.

Foram encontrados trinta e três trabalhos, em catorze programas de pós-graduação. Do total, vinte e três são resultado de Dissertações de mestrado. No Quadro 2 estão organizadas as Dissertações encontradas nos programas de Pós-Graduação em Geografia.

\begin{tabular}{|c|c|c|c|}
\hline Instituição & Título & Autor & Ano \\
\hline UFBA & $\begin{array}{l}\text { O conceito de urbano e as cidades de pequeno porte no } \\
\text { semiárido baiano: Novo Triunfo, Santa Brígida e Sítio } \\
\text { do Quinto }\end{array}$ & $\begin{array}{l}\text { Diva } \mathrm{M}^{\mathrm{a}} . \mathrm{F} \\
\text { LOPES }\end{array}$ & 2005 \\
\hline UFPB & $\begin{array}{l}\text { A Cidade de Coremas-PB: Geografia Histórica de uma } \\
\text { Pequena Cidade }\end{array}$ & $\begin{array}{l}\text { Rita de Cássia } \\
\text { G. de } \\
\text { ANDRADE }\end{array}$ & 2008 \\
\hline \multirow{3}{*}{ UFRN } & $\begin{array}{l}\text { Cidades Pequenas, Grandes Problemas: Perfil Urbano } \\
\text { do Agreste Potiguar }\end{array}$ & $\begin{array}{c}\text { Francisco E. } \\
\text { GONÇALVES }\end{array}$ & 2005 \\
\hline & $\begin{array}{l}\text { A produção do espaço das pequenas cidades do Seridó } \\
\text { Potiguar }\end{array}$ & $\begin{array}{l}\text { Maria Suely da } \\
\text { S. MEDEIROS }\end{array}$ & 2005 \\
\hline & $\begin{array}{l}\text { Na Esquina do Brasil: uma leitura geográfica da } \\
\text { (re)construção do território }\end{array}$ & $\begin{array}{l}\text { Márcia Silva de } \\
\text { MEDEIROS }\end{array}$ & 2002 \\
\hline \multirow[b]{2}{*}{ UFMG } & $\begin{array}{l}\text { Da migração à não migração: o exemplo de pequenas } \\
\text { cidades da zona da mata mineira }\end{array}$ & $\begin{array}{c}\text { Severina Sarah } \\
\text { LISBOA }\end{array}$ & 2008 \\
\hline & $\begin{array}{l}\text { Sistemas de informações geográficas para auxiliar no } \\
\text { desenvolvimento local, endógeno e sustentável de } \\
\text { municípios de pequeno porte: o caso de Jaboticatubas }\end{array}$ & \begin{tabular}{|c|} 
Márcio \\
Marques \\
MACHADO \\
\end{tabular} & 2001 \\
\hline \multirow{3}{*}{ UFU } & $\begin{array}{l}\text { Plano Diretor: uma metodologia de elaboração para } \\
\text { municípios de pequeno porte }\end{array}$ & $\begin{array}{l}\text { Viviane dos G. } \\
\text { Alvim NUNES }\end{array}$ & 2005 \\
\hline & $\begin{array}{l}\text { Tupaciguara 'Lá Tem': revitalização urbana e cultura } \\
\text { popular }\end{array}$ & $\begin{array}{l}\text { Alessandra R. } \\
\text { FERREIRA }\end{array}$ & 2005 \\
\hline & $\begin{array}{l}\text { A cidade local no contexto da globalização: o exemplo } \\
\text { de Machado/MG }\end{array}$ & $\begin{array}{l}\text { Nádia C. da S. } \\
\text { MELLO }\end{array}$ & 2001 \\
\hline
\end{tabular}




\begin{tabular}{|c|c|c|c|}
\hline UFRJ & $\begin{array}{l}\text { Transformações em Curso no Perfil Econômico e } \\
\text { Sociospacial de Cidades de Pequeno Porte: o Exemplo } \\
\text { de Bom Jesus de Itabapoana no Noroeste Fluminense }\end{array}$ & $\begin{array}{l}\text { Maria Alice } \\
\text { Alkmim } \\
\text { ANDRADE } \\
\end{array}$ & 2001 \\
\hline UNICAMP & $\begin{array}{l}\text { Espaço vivido, cotidiano e qualidade de vida em } \\
\text { pequenos municípios. Caso: município de Urupês (SP) }\end{array}$ & $\begin{array}{l}\text { Sérgio H. R. } \\
\text { CRIVELARO }\end{array}$ & 2008 \\
\hline \multirow{2}{*}{$\begin{array}{l}\text { UNESP } \\
\text { Pres. } \\
\text { Prudente }\end{array}$} & Segregação socioespacial em cidades pequenas & \begin{tabular}{|c|} 
Cláudia \\
Marques \\
ROMA \\
\end{tabular} & 2008 \\
\hline & $\begin{array}{l}\text { Autoconstrução em Sertanópolis: resolução do } \\
\text { problema da moradia ou exaustão da força de trabalho? }\end{array}$ & $\begin{array}{l}\text { Sueli Aparecida } \\
\text { LOPES }\end{array}$ & 2000 \\
\hline \multirow{2}{*}{$\begin{array}{l}\text { UNESP } \\
\text { Rio Claro }\end{array}$} & $\begin{array}{l}\text { Os espaços de medo e os de castigo nas pequenas } \\
\text { cidades do estado de São Paulo: o caso Itirapina }\end{array}$ & $\begin{array}{c}\text { Érico } \\
\text { SORIANO } \\
\end{array}$ & 2007 \\
\hline & $\begin{array}{l}\text { Planejamento ambiental para cidades pequenas: o caso } \\
\text { de Perdões - MG }\end{array}$ & $\begin{array}{l}\text { Mariana A. do } \\
\text { NASCIMENTO }\end{array}$ & 2004 \\
\hline USP & $\begin{array}{l}\text { Transformações urbanas recentes em Tiradentes-MG: } \\
\text { anos } 80 \text { e } 90 \text { do século XX }\end{array}$ & $\begin{array}{l}\text { Hélcio Ribeiro } \\
\text { CAMPOS }\end{array}$ & 2006 \\
\hline UEM & $\begin{array}{l}\text { A (Re) Produção do espaço urbano de Dois Vizinhos no } \\
\text { contexto do Sudoeste paranaense }\end{array}$ & $\begin{array}{c}\text { Tatiane } \\
\text { SAFFNAUER }\end{array}$ & 2005 \\
\hline UEL & $\begin{array}{l}\text { Jaguapitã-PR: pequena cidade da rede urbana norte- } \\
\text { paranaense especializada na produção industrial de } \\
\text { mesas para bilhar }\end{array}$ & $\begin{array}{l}\text { Léia Aparecida } \\
\text { Veiga PINTO }\end{array}$ & 2007 \\
\hline UFSC & A industrialização em Sombrio: gênese e evolução & $\begin{array}{l}\text { L. M. V. } \\
\text { BELTRÃO }\end{array}$ & 2001 \\
\hline \multirow{3}{*}{ UFSM } & $\begin{array}{l}\text { Os papéis urbanos nas pequenas cidades da região da } \\
\text { Quarta Colônia-RS }\end{array}$ & $\begin{array}{l}\text { Silvane } \\
\text { SPOLAOR }\end{array}$ & 2010 \\
\hline & $\begin{array}{l}\text { O sistema termodinâmico do clima urbano de Nova } \\
\text { Palma, RS: contribuição ao clima urbano de cidades } \\
\text { pequenas }\end{array}$ & \begin{tabular}{|c|} 
Paula \\
Savegnago \\
ROSSATO \\
\end{tabular} & 2010 \\
\hline & $\begin{array}{l}\text { Construção do espaço urbano da pequena cidade: um } \\
\text { estudo sobre São Sepé-RS }\end{array}$ & $\begin{array}{c}\text { Fabiano Bolzan } \\
\text { SCHERER }\end{array}$ & 2009 \\
\hline
\end{tabular}

Quadro 2: Dissertações sobre cidades pequenas defendidos nas universidades brasileiras entre os anos de 2000 e 2010.

Fonte: Consulta banco de Teses - CAPES.

Organização: Orlando Moreira Junior, 2014.

Quanto às Teses, foram encontradas dez pesquisas, registradas no Quadro 3. Vale observar que os trabalhos estão concentrados na região 
Sudeste, cujos referenciais empíricos abrangem, especialmente, o interior paulista, goiano, mineiro e sul-riograndense.

\begin{tabular}{|c|c|c|c|}
\hline sstituição & Título & Autor & A \\
\hline \multirow{3}{*}{ UFU } & $\begin{array}{l}\text { A Pequena Cidade nas Teias da Aldeia Global: as } \\
\text { Relações e Especificidades Sociopolíticas nas } \\
\text { Pequenas Cidades de Estrela do Sul, Cascalho Rico } \\
\text { e Grupiara-MG }\end{array}$ & $\begin{array}{l}\text { Win } \\
\text { Alme }\end{array}$ & \\
\hline & $\begin{array}{l}\text { Pequenas cidades da microrregião geográfica de } \\
\text { Catalão (GO): análises de seus conteúdos e } \\
\text { considerações teórico-metodológicas }\end{array}$ & $\begin{array}{r}\text { Nágela } \mathrm{Ap} \\
\mathrm{ME}\end{array}$ & \\
\hline & $\begin{array}{l}\text { Cidade Média e Região: o significado de Montes } \\
\text { Claros no Norte de Minas Gerais }\end{array}$ & $\begin{array}{r}\text { Ane } \\
\text { PE }\end{array}$ & \\
\hline UFRJ & -campo, urbano-rural: uma contribuição ao & $\begin{array}{l}\text { Mar } \\
\text { Palm }\end{array}$ & 20 \\
\hline USP & calor em cidade de pequeno porte: Caso de & $\begin{array}{r}\text { Edson } \\
\text { FIA }\end{array}$ & \\
\hline \multirow{3}{*}{$\begin{array}{l}\text { UNESP } \\
\text { Pres. } \\
\text { Prudente }\end{array}$} & $\begin{array}{l}\text { Sanclerlândia-GO: do povoado do Cruzeiro às } \\
\text { novas centralidades }\end{array}$ & $\begin{array}{r}\text { Elson } \mathrm{R} \\
\text { OLA }\end{array}$ & \\
\hline & $\begin{array}{l}\text { Pensando os papéis e significados das pequenas } \\
\text { cidades do noroeste do Paraná }\end{array}$ & $\begin{array}{l}\text { Angela Maria } \\
\text { ENDLICH }\end{array}$ & \\
\hline & $\begin{array}{l}\text { Pequenas cidades na região de Catanduva-SP: } \\
\text { papéis urbanos, reprodução social e produção de } \\
\text { moradias }\end{array}$ & Mara Luc & 20 \\
\hline $\begin{array}{c}\text { UNESP } \\
\text { Rio Claro }\end{array}$ & $\begin{array}{l}\text { Pequenos municípios e pequenas cidades do estado } \\
\text { do Rio Grande do Sul: contrastes, perfil do } \\
\text { desenvolvimento e da qualidade de vida, 1980-2000 }\end{array}$ & $\begin{array}{l}\text { Vilma Dominga M. } \\
\text { FIGUEIREDO }\end{array}$ & 20 \\
\hline UFSC & $\begin{array}{l}\text { Inundações em Venâncio Aires/RS: interações entre } \\
\text { as dinâmicas natural e social na formação de riscos } \\
\text { socioambientais urbanos }\end{array}$ & $\begin{array}{c}\text { Erika } \\
\text { COLLISCHONN }\end{array}$ & 2009 \\
\hline
\end{tabular}

Quadro 3: Teses sobre cidades pequenas defendidos nas universidades brasileiras entre os anos de 2000 e 2010.

Fonte: Consulta banco de Teses - CAPES.

Organização: Orlando Moreira Junior, 2014.

Importante verificar a distribuição do total de Dissertações e Teses pelo país. Cinco foram realizadas no Nordeste, enquanto as demais se concentram no Centro-Sul. Destaque para a Universidade Federal de Uberlândia e para a UNESP de Presidente Prudente, com os maiores números de pesquisas efetuadas. Essa espacialização é relevante para 
pensar não somente onde tem predominado os estudos, mas quais regiões tem sido alvo preferencial dos mesmos.

Uma observação relevante é a maior ocorrência de trabalhos nos programas situados em lugares de expansão de cidades médias, como são os casos de Uberlândia e Presidente Prudente. Trata-se de centros acadêmicos que vêm demonstrando uma preocupação na leitura de espaços não metropolitanos, promovendo estudos centrados nas modificações do sistema urbano, no contexto regional e nos processos espaciais de rearranjo nas articulações entre as cidades, hierárquicas ou não. De tal modo, o estudo de cidades médias e das pequenas, que a elas se articulam, tem representado, num período recente, a necessidade de incluir novos elementos para a compreensão dos arranjos espaciais e da complexidade que envolve a conformação atual do território brasileiro.

A ausência da região Amazônica é um fato preocupante neste aspecto, pois possui características particulares que precisariam ser incluídas na reflexão geográfica sobre o tema. Avaliando a situação da região Norte é possível identificar que houve, entre 1980 e 2010, um crescimento de 55\% no número de municípios, passando de 203 para 449. A opção pela comparação com a década de 1980 foi justamente por se tratar da década referente à nova constituinte, que atribuiu maior poder de decisão aos estados e municípios. Considerando a classe populacional, os dados do censo revelam que o número de municípios com população inferior a 2 mil habitantes passou de 1 para 10 , nesse período. $\mathrm{O}$ aumento no número de municípios nas demais classes também é evidente: 109 municípios a mais na faixa entre 2 e 10 mil habitantes; e 36, na de 10 a 20 mil habitantes.

Portanto, houve a expansão do número de municípios com sedes nas cidades pequenas na região. Mesmo com essa evidência empírica, as particularidades acerca das características e interações próprias de cidades pequenas neste cenário regional não têm sido alvo de pesquisas acadêmicas. Uma das explicações para isto pode estar no número de Programas de Pós-Graduação em Geografia existentes na região: cinco (Universidade Federal do Amazonas; Universidade Federal do Pará; Fundação Universidade Federal de Roraima; Fundação Universidade Federal do Tocantins; Universidade Federal de Rondônia), todos na modalidade mestrado, além de se tratar, em sua maioria, de programas recentes. Tanto as áreas de concentração desses programas quanto as linhas 
de pesquisa possuem temas relacionados aos estudos da Amazônia, especialmente naquilo que abrange sua dinâmica territorial e ambiental.

De modo geral, o levantamento das pesquisas acadêmicas demonstrou que os temas abordados por elas são variados e observa-se, a partir desta elaboração, que apesar da diversidade urbana no país e do significativo número de cidades pequenas Brasil afora, essa temática tem sido apreciada de modo bastante concentrado. Apesar disso é possível identificar algumas tendências que têm guiado a abordagem geográfica nos estudos sobre cidades pequenas, como nos esforçaremos para fazer a seguir.

\section{As principais tendências analíticas}

Inicialmente, a elaboração de um quadro que sintetize o tema central e os caminhos metodológicos que guiaram o pensamento das Dissertações e Teses permite identificar a direção que os estudos a respeito de cidades pequenas têm seguido, e os desafios que ainda perduram ante esse objeto de pesquisa. Este exercício analítico é apresentado no Quadro 4, em anexo.

Neste quadro estão presentes, de forma sucinta, os principais aportes teórico-metodológicos das pesquisas elencadas anteriormente e que contribuíram para a análise das tendências dos estudos sobre cidades pequenas na Geografia brasileira. Um aspecto que chama a atenção na análise do quadro é o fato de haver onze pesquisas que tiveram como referencial empírico cidades pequenas localizadas no estado de Minas Gerais e seis no Rio Grande do Sul. Ao mesmo tempo em que a região norte sequer aparece como referencial empírico, como foi tratado anteriormente.

Com base na síntese apresentada no Quadro 4 é possível observar e ver as semelhanças e diferenças na análise do urbano em cidades pequenas, do mesmo modo que se tem a possibilidade de observar as tendências das leituras que se seguem sobre o tema. Para tanto, utilizaremos as proposições de Soares e Melo (2010) quando apontam que uma leitura atenta sobre pequena cidade no período contemporâneo deve levar em conta sete aspectos, que pontuam alguns parâmetros qualitativos com relação ao assunto em questão: 
- A inserção no mundo da globalização: esta é uma abordagem que estabelece um elo entre o local e o global, ante as inovações tecnológicas e a inserção econômica globalizada. Nesta direção, Capel (2009) também procurou estabelecer uma relação entre a urbanização e as transformações socioespaciais diante do contexto da globalização. Dentre as pesquisas selecionadas, um esforço sobre esta perspectiva analítica é possível de ser observada, por exemplo, em Mello (2001), Endlich (2006) e Bacelar (2008). Temas como gestão territorial, especialização produtiva, influência do meio técnico-científico-informacional, vantagens competitivas, entre outros, figuram entre os principais neste grupo.

- A relação entre o poder público local e a população: de acordo com Soares e Melo (2010), as relações entre a população e os agentes políticos são marcadas por dependência, assistencialismo, demandas e atenção pessoais (questões são tratadas no âmbito da pessoalidade). Andrade (2001), Endlich (2006), Bacelar (2008) e Figueiredo (2008) são exemplos de trabalhos que perpassam o entendimento dessas relações em cidades pequenas.

- A relação com a natureza: essa temática está entre as que menos têm sido alvo das considerações acadêmicas. Tal abordagem também é variada. Em Bacelar (2008), Nascimento (2004) e Machado (2001) é possível ver uma preocupação em se estabelecer uma leitura das cidades pequenas com as questões ambientais. Destacam-se, ainda, os estudos sobre o clima urbano em cidades pequenas, como em Rossato (2010) e Fialho (2009), bem como a preocupação com a vulnerabilidade ambiental, numa visão prospectiva de Collischonn (2009). Em suma, os estudos estão voltados para a análise do clima, na escala local, e a preocupação com o planejamento e gestão urbana e regional.

- O entorno rural e as ruralidades: a relação cidade-campo e a discussão entre o urbano e a cidade estão entre as mais apreciadas pelos geógrafos que estudam cidades pequenas, especialmente porque se trata de estudos em áreas não metropolitanas ou localizadas distantes de grandes centros econômicos. Além de se tratar de um elemento muito utilizado nos esforços para a construção de um conceito, os aspectos rurais e a relação estreita estabelecida entre as cidades pequenas e o campo figuram como possibilidades analíticas para avaliar o tênue limiar que se estabelece entre a cidade e o campo; bem como o forte vínculo existente com o rural se manifesta também na paisagem urbana, tanto na morfologia das cidades 
quanto no modo de vida da população. Pesquisas como as de Bernardelli (2004), Lopes (2005), Lima (2007) e Roma (2008) caminham nesta direção.

- A dependência do sistema urbano-regional: de acordo com Soares e Melo (2010), o sistema urbano-regional está ligado a três aspectos fundamentais: a densidade (relação entre o número de centros urbanos e o território); a topologia (relação entre o número de ligações que representaram o fluxo de bens e serviços entre as cidades integrantes do sistema urbano); e a hierarquia (identifica o ordenamento espacial das funções urbanas). Oliveira (2003), Bernardelli (2004), Medeiros (2005), Saffnauer (2005), Endlich (2006), Lima (2007), Pereira (2007), Pinto (2007), Roma (2008), Olanda (2010) e Spolaor (2010) transitam por esses aspectos ao tratarem as cidades a partir da rede urbana e do contexto regional, fazendo pensar também nas escalas, nos atores e nos dilemas do planejamento e da gestão do território. Essa tem sido a abordagem mais apreciada pelos geógrafos nos estudos acadêmicos, sendo que quaisquer outros enfoques, geralmente, são considerados a partir da relação entre o espaço regional e intraurbano.

- O envelhecimento e a involução populacional: a questão demográfica desponta como um dos critérios para a determinação do que poderia ser considerada uma cidade pequena. Diversos trabalhos procuram avaliar a dinâmica demográfica em cidades pequenas. No que concerne ao estudo do envelhecimento populacional, Figueiredo (2008) e Soriano (2007) procuram registrar esse acontecimento em seus referenciais empíricos. Já Lisboa (2008), tem por preocupação maior o estudo da dinâmica migratória que envolve cidades pequenas. Quanto à involução populacional, a maioria dos trabalhos que fazem uma análise da dinâmica demográfica apresenta a ocorrência ou não desse fenômeno. A questão demográfica possui relevância, na maioria dos trabalhos, apenas como limiar para definir o que está sendo considerado pequeno. Porém, vem sendo utilizada de forma limitada. Trata-se de um aspecto que merece ser explorado com maior atenção, considerando as variáveis que compõem a dinâmica demográfica como o crescimento populacional e a estrutura por sexo-idade, bem como as tendências migratórias que envolvem esses espaços. Este conjunto possui particularidades expressivas e tem desdobramentos espaciais significativos para essas realidades urbanas. 
- Os aspectos de sociabilidade na pequena cidade: ao se pensar em cidade pequena aludimos a relações mais próximas de sociabilidade entre as pessoas. Hipoteticamente, o tamanho territorial das pequenas cidades permitiria uma maior proximidade entre seus moradores, que vivenciam os mesmos espaços públicos: a igreja, a praça, o centro, entre outros. Contudo, as alterações das relações sociais da cidade e a fragilidade da unidade urbana não se dão apenas nas grandes e médias cidades, mas na sociedade como um todo. Ferreira (2005), Endlich (2006), Soriano (2007), Bacelar (2008), Roma (2008) e Crivelaro (2008) apresentam, de modo diferenciado, alguns exemplos dos desdobramentos socioespaciais advindos desse aspecto em seus referenciais empíricos.

Diversas considerações poderiam ser apresentadas aqui devido à amplitude de questões que envolvem o tema que se propôs debater. Todavia, elencamos três pontos para encerrar a análise que se desenvolveu até aqui.

Primeiramente, a complexidade que envolve o tema. Por conta disso, no caso específico das cidades pequenas, Sposito (2004) afirma que não há como estudar seus papéis e significados sem o seu entorno, pois esses só podem ser compreendidos mediante a composição desse cenário. Isso ajuda a explicar também a variedade de recortes populacionais empregados para definir os referenciais empíricos nas pesquisas. É possível se deparar tanto com núcleos urbanos com menos de 2 mil habitantes quanto com alguns casos particulares de cidades que chegam a ultrapassar 50 mil, que estão sendo consideradas cidades pequenas pelo contexto no qual se inserem, ou de acordo com os objetivos que foram definidos pelo pesquisador.

Diante disso, o segundo ponto procura refletir metodologicamente sobre as pesquisas: as abordagens têm se desenvolvido, principalmente, a partir tanto do espaço inter quanto do intraurbano. O primeiro com foco nos efeitos externos da cidade (rede urbana, relações com a região ou com outras cidades, lógica da respectiva participação do espaço etc.), e o segundo estaria voltado para a dinâmica interna do tecido urbano (o mercado imobiliário, a morfologia, as funções, o crescimento, etc.). Em linhas gerais, os estudos sobre cidades pequenas têm priorizado cinco eixos principais: o contexto urbano-regional; os ramos das atividades econômicas representativas da atuação dos agentes econômicos; a presença/ausência/insuficiência de equipamentos, infraestruturas e serviços 
urbanos; a dinâmica demográfica e o mercado de trabalho; e as lógicas gerais e particulares que engendram a produção do espaço urbano e da moradia.

$\mathrm{Na}$ abordagem a partir do espaço interurbano tem-se privilegiado a definição dos papéis e significados urbanos ante o contexto regional, principalmente a partir dos aspectos econômicos. Enquanto na abordagem com foco na dinâmica interna das cidades, a leitura a partir da produção do espaço urbano tem se despontado. Essa abordagem é claramente definida em Beltrão (2001), Oliveira (2002), Bernardelli (2004), Gonçalves (2005), Saffnauer (2005), Scherer (2009). Ademais, temas relacionados são encontrados, por exemplo, na análise da produção de moradia e autoconstrução (LOPES, 2000; BERNARDELLI, 2004), nos aspectos culturais e históricos da representação do espaço e do cotidiano (FERREIRA, 2005; ANDRADE, 2008), ou na própria preocupação com as normas e os planos para gestão e planejamento da cidade (NASCIMENTO, 2004; NUNES, 2005; FERREIRA, 2005).

Por fim, como estamos tratando de tendências e do espaço que as cidades pequenas vêm tendo na Geografia brasileira, é importante destacar que essas pesquisas acadêmicas dão origem também a outras formas de divulgação da temática no meio cientifico, seja em forma de trabalhos em congressos, livros ou artigos em periódicos. Os pesquisadores aqui citados procuram divulgar seus trabalhos e inserir o tema nos estudos geográficos. Mas eles ainda são pontuais, sendo preciso construir uma agenda em comum para os estudos acerca das cidades pequenas, tanto do ponto de vista teórico-conceitual quanto do metodológico.

\section{Considerações finais}

O estudo das cidades fortaleceu-se na Geografia Regional Francesa nas monografias regionais -, sobretudo, os estudos de regiões urbanas. $\mathrm{O}$ estudo locacional despontou com maior relevância para a disciplina, que priorizava a distribuição dos fenômenos no espaço. A evolução urbana, o sítio, as funções e a região de influência das cidades estão entre os temas que envolviam a análise geográfica. $O$ que se percebe é que isso não perdeu significado. Os estudos no âmbito regional não deixaram de existir, pelo contrário, eles permaneceram até a atualidade, mas com modificações inclusive no sentido que se atribui ao conceito de região. 
Apesar de ainda ser minoria no estudo do urbano e da urbanização, a cidade pequena vem ganhando espaço dentro das pesquisas acadêmicas. $\mathrm{O}$ espaço dela tem sido abordado com foco no contexto regional e priorizando diferentes dimensões, especialmente a populacional, funcional e espacial.

$\mathrm{Na}$ Geografia, o espaço enquanto objetivação geográfica do estudo da cidade apresenta várias facetas que permitem que seja analisado de forma multivariada. Diferentes modos de encarar o espaço urbano, os seus habitantes e as suas dinâmicas têm permeado a abordagem no interior do pensamento geográfico. Nos estudos dedicados às cidades pequenas, notase que a influência da leitura a partir da produção do espaço vem ganhando destaque.

Mas, se as cidades são pequenas, os desafios ainda são grandes. São igualmente utilizadas diferentes definições: pequenas cidades, cidades pequenas, cidades de pequeno porte ou cidades locais. Da mesma forma, diferentes classes de tamanho populacional são definidas para delimitar o que está sendo chamada de cidade pequena. A falta de um consenso é expressão direta das limitações teórico-conceituais e metodológicas com as quais os pesquisadores têm se deparado na leitura dessas realidades urbanas.

É preciso, portanto, avançar nos estudos e superar as lacunas existentes. A principal é constituir uma agenda comum de pesquisa, como ocorre, por exemplo, nos estudos tanto das metrópoles quanto das cidades médias. O Observatório das Metrópoles e a Rede de Pesquisadores sobre Cidades Médias (ReCiMe) representam esforços em construir uma metodologia unificada de pesquisa, respectivamente, para as chamadas cidades médias e para as principais regiões metropolitanas do país. Isso tem permitido a comparabilidade, cujos resultados extrapolam a constatação, descrição, classificação e análise dos fenômenos, atingindo o nível conceitual e metodológico. Isso deve e pode ser pensado também para as cidades pequenas.

Os desafios ainda são diversos. Os temas que figuram como possibilidades para pesquisas teórico-conceituais e empíricas também são amplos e variados. A Geografia precisa corrigir esse hiato que parece permanecer em aberto e que representa uma faceta importante para a compreensão da urbanização do país. Existe um campo significativo que merece espaço na agenda dos geógrafos. É preciso avançar em pesquisas 
em contextos regionais diferenciados: regiões metropolitanas, regiões de fronteiras, regiões ribeirinhas, entre outros. Isso é fundamental para a compreensão teórico-conceitual sobre as cidades pequenas e a vida urbana, de um lado, e das questões e problemáticas que já se manifestam nesses espaços urbanos, por outro.

\section{TENDÊNCIAS NAS PESQUISAS GEOGRÁFICAS SOBRE CIDADES PEQUENAS NO BRASIL: APONTAMENTOS PARA ANÁLISE}

Resumo: Este artigo procura refletir acerca das principais tendências que o tema cidades pequenas assume na ciência geográfica brasileira, tendo como base as pesquisas de mestrado e doutorado das principais Universidades brasileiras. Para tanto, inicialmente, é realizada uma leitura da diversidade urbana no Brasil, que contempla cidades de variados tamanhos territorial e populacional. Em seguida é apresentado um levantamento das pesquisas acadêmicas publicadas no período de 2000 a 2010 nos programas de pós-graduação em Geografia no país. Por fim, é efetuada uma análise que visa apontar as principais perspectivas analíticas que permeiam o estudo das cidades pequenas na pós-graduação.

Palavras-chave: cidades pequenas, pesquisas de Pós-Graduação em Geografia, Geografia Urbana.

\section{TRENDS IN GEOGRAPHICAL RESEARCH ON SMALL TOWNS IN BRAZIL: NOTES FOR ANALYSIS}

Abstract: This article reflects on the key trends that the topic has been gaining in small towns Brazilian geographical science, based on the research masters and doctoral major Brazilian universities. Is initially performed a reading of urban diversity in Brazil, which includes the cities of varying sizes, territorial and population. Then we present a survey of academic research published in the period 2000 to 2010 in the graduate programs in Geography in the country. Finally an analysis is performed aimed at pointing out the main analytical perspectives on the study of small towns in graduate school.

Keywords: small towns, postgraduate researches in Geography, Urban Geography. 


\section{Bibliografia}

ANDRADE, M. A. A. (2001) Transformações em Curso no Perfil Econômico e Socioespacial de Cidades de Pequeno Porte: o Exemplo de Bom Jesus de Itabapoana no Noroeste Fluminense. Dissertação (Mestrado em Geografia) - Universidade Federal do Rio de Janeiro, Rio de Janeiro.

ANDRADE, R. C. G. (2008) A Cidade de Coremas - PB: Geografia Histórica de uma Pequena Cidade. 184f. Dissertação (Mestrado em Geografia) - Universidade Federal da Paraíba, João Pessoa.

BACELAR, W. K. (2008) A Pequena Cidade nas Teias da Aldeia Global: as Relações e Especificidades Sócio-Políticas nas Pequenas Cidades de Estrela do Sul, Cascalho Rico e Grupiara - MG. 411p. Tese (Doutorado em Geografia) - Universidade Federal de Uberlândia, Uberlândia.

BELTRÃO, L. M. V. (2001) A industrialização em Sombrio: gênese e evolução. 162f. Dissertação (Mestrado em Geografia) - Universidade Federal de Santa Catarina, Florianópolis.

BERNARDELli, M. L. F. H. (2004) Pequenas Cidades na Região de Catanduva-SP: papéis urbanos, reprodução social e produção de moradias. 2004. 347p. Tese (Doutorado em Geografia) - Universidade Estadual Paulista, UNESP, Presidente Prudente.

CAMPOS, H. R. (2006) Transformações urbanas recentes em Tiradentes$M G$ : anos 80 e 90 do século XX. 183 f. Dissertação (Mestrado em Geografia) - Universidade de São Paulo, São Paulo.

CAPEL, H. (2009) Las pequeñas ciudades en la urbanización generalizada y ante la crisis global. Investigaciones Geográficas, 70, México, p. 07-32.

COLLISCHONN, E. (2009) Inundações em Venâncio Aires/RS: interações entre as dinâmicas natural e social na formação de riscos socioambientais urbanos. 327 f. Tese (Doutorado em Geografia) - Centro de Filosofia e Ciências Humanas, Universidade Federal de Santa Catarina, Florianópolis.

CRIVELARO, S. H. R. (2008) Espaço vivido, cotidiano e qualidade de vida em pequenos municípios. Caso: município de Urupês (SP). 113f. Dissertação (Mestrado em Geografia) - Universidade de Campinas, Campinas.

ENDLICH, A. M. (2006) Pensando os Papéis e Significados das Pequenas Cidades do Noroeste do Paraná. 2006. 507 f. Tese (Doutorado em Geografia) - Universidade Estadual Paulista, Presidente Prudente. 
FERREIRA, A. R. (2005) Tupaciguara 'Lá Tem': revitalização urbana e cultura popular. Dissertação (Mestrado em Geografia) - Universidade Federal de Uberlândia, Uberlândia.

FERREIRA, L. R. (2009) Transformações na paisagem urbana de Santa Vitória do Palmar-RS: relações sociais, políticas de habitação e a produção da cidade. 167 f. Dissertação (Mestrado em Geografia) - Universidade Federal do Rio Grande do Sul, Porto Alegre.

FIALHO, E. S. (2009) Ilha de calor em cidade de pequeno porte: Caso de Viçosa, na Zona da Mata Mineira. 259 f. Tese (Doutorado em Geografia Física) Faculdade de Filosofia, Ciência, Letras e Ciências Humanas, Universidade de São Paulo, São Paulo.

FIGUEIREDO, V. D. M. (2008) Pequenos Municípios e Pequenas Cidades do Estado do Rio Grande do Sul: contrastes, perfil do desenvolvimento e de qualidade de vida, 1980-2000. $265 \mathrm{f}$. Tese (Doutorado em Geografia) - Universidade Estadual Paulista, Rio Claro.

GONÇALVES, F. E. (2005) Cidades Pequenas, Grandes Problemas: Perfil Urbano do Agreste Potiguar. 173f. Dissertação (Mestrado em Geografia) - Universidade Federal do Rio Grande Norte, Natal.

LIMA, M. H. P. (2008) Cidade-campo, urbano-rural: uma contribuição ao debate. 271f. Tese (Doutorado em Geografia) - Universidade Federal do Rio de Janeiro, Rio de Janeiro.

LISBOA, S. S. (2008) Da migração à não-migração: o exemplo de pequenas cidades da zona da mata mineira. $133 \mathrm{f}$. Dissertação (Mestrado em Geografia) - Universidade Federal de Minas Gerais, Belo Horizonte.

LOPES, D. M. F. (2005) O conceito de urbano e as cidades de pequeno porte no semiárido baiano: Novo Triunfo, Santa Brígida e Sítio do Quinto. 175 f. Dissertação (Mestrado em Geografia) - Universidade Federal da Bahia, Salvador.

LOPES, S. A. (2000) Autoconstrução em Sertanópolis: resolução do problema da moradia ou exaustão da força de trabalho? $300 \mathrm{f}$. Dissertação (Mestrado em Geografia) - Faculdade de Ciências e Tecnologia, Universidade Estadual Paulista, Presidente Prudente.

MACHADO, M. M. (2001) Sistemas de informações geográficas para auxiliar no desenvolvimento local, endógeno e sustentável de municípios de pequeno porte: o caso de Jaboticatubas. $141 \mathrm{f}$. Dissertação (Mestrado) Universidade Federal de Minas Gerais, Belo Horizonte. 
MEDEIROS, M. S. S. (2005) A Produção do Espaço das pequenas cidades do Seridó Potiguar. 2005. 152 f. Dissertação (Mestrado em Geografia) - Universidade Federal do Rio Grande Norte, Natal.

MELLO, N. C. S. (2001) A cidade local no contexto da globalização: o exemplo de Machado/MG. Dissertação (Mestrado em Geografia) Universidade Federal de Uberlândia, Uberlândia.

MELO, N. A. (2008) Pequenas cidades da microrregião geográfica de Catalão (GO): análises de seus conteúdos e considerações teóricometodológicas. 527 f. Tese (Doutorado em Geografia) - Universidade Federal de Uberlândia, Uberlândia.

NASCIMENTO, M. A. (2004) Planejamento ambiental para cidades pequenas: o caso de Perdões - MG. 2004. 158 f. Dissertação (Mestrado em Geografia) - Universidade Estadual Paulista, Rio Claro.

NUNES, V. G. A. (2005) Plano Diretor: uma metodologia de elaboração para municípios de pequeno porte. 223 f. Dissertação (Mestrado em Geografia) - Universidade Federal de Uberlândia, Uberlândia.

OLANDA, E. R. (2010) Sanclerlândia-GO: do povoado do Cruzeiro às novas centralidades. $208 \mathrm{f}$. Tese (Doutorado em Geografia) - Faculdade de Ciências e Tecnologia, Universidade Estadual Paulista, Presidente Prudente.

OLIVEIRA, M. S. (2002) Na Esquina do Brasil: uma leitura geográfica da (re) construção do território. 2002. 217f. Dissertação (Mestrado em Geografia) - Universidade Federal do Rio Grande Norte, Natal.

PEREIRA, A. M. (2007) Cidade Média e Região: o significado de Montes Claros no Norte de Minas Gerais. 2007. 350f. Tese (Doutorado em Geografia) - Universidade Federal de Uberlândia, Uberlândia.

PINTO, L. A. V. (2007) Jaguapitã - PR: pequena cidade da rede urbana norte- paranaense especializada na produção industrial de mesas para bilhar. Dissertação (Mestrado em Geografia, Meio Ambiente e Desenvolvimento) - Universidade Estadual de Londrina, Londrina (PR).

ROMA, C. M. (2008) Segregação Socioespacial em Cidades Pequenas. 156 f. Dissertação (Mestrado em Geografia) - Universidade Estadual Paulista, Presidente Prudente.

ROSSATO, P. S. (2010) O sistema termodinâmico do clima urbano de Nova Palma, RS: contribuição ao clima urbano de cidades pequenas. 2010. 
119 f. Dissertação (Mestrado em Geografia) - Universidade Federal de Santa Maria, Santa Maria.

SAFFNAUER, T. (2005) A (Re) Produção do espaço urbano de Dois Vizinhos no contexto do Sudoeste paranaense. Dissertação (Mestrado em Geografia) - Universidade Estadual de Maringá, Maringá.

SANTOS, M. (1994) A Urbanização Brasileira. São Paulo: Hucitec.

SOARES, B. R., MELO, N. A. (2010) Cidades médias e pequenas: reflexões sobre os desafios no estudo dessas realidades socioespaciais. In: LOPES, D. M. F.; HENRIQUE, W. (orgs.) Cidades médias e pequenas: teorias, conceitos e estudos de caso. Salvador: SEI, p. 229-250.

SORIANO, É. (2007) Os espaços de medo e os de castigo nas pequenas cidades do estado de Sáo Paulo: o caso Itirapina. $157 \mathrm{f}$. Dissertação (Mestrado em Geografia) - Universidade Estadual Paulista, Rio Claro.

SPOLAOR, S. (2010) Os papéis urbanos nas pequenas cidades da região da Quarta Colônia - RS. 192 f. Dissertação (Mestrado em Geografia) Universidade Federal de Santa Maria, Santa Maria.

SPOSITO, M. E. B. (2004) O Chão em Pedaços: urbanização, economia e cidades no Estado de São Paulo. 508 f. Tese (Livre Docência) Universidade Estadual Paulista, Presidente Prudente. 


\section{Anexo}

Quadro 4: Síntese da abordagem realizada nas Dissertações e Teses analisadas

\begin{tabular}{|c|c|c|c|c|}
\hline Autor & Título & Objetivos & $\begin{array}{l}\text { Referencial } \\
\text { empírico }\end{array}$ & Metodologia \\
\hline $\begin{array}{l}\text { Maria } \\
\text { Helena } \\
\text { Palmer } \\
\text { LIMA }\end{array}$ & $\begin{array}{c}\text { Cidade-campo, } \\
\text { urbano-rural: uma } \\
\text { contribuição ao } \\
\text { debate a partir de } \\
\text { pequenas cidades em } \\
\text { Minas Gerais }\end{array}$ & \begin{tabular}{|c|} 
Contribuir para o \\
debate a respeito da \\
definição de cidade \\
no Brasil, tendo em \\
vista as profundas \\
transformações nas \\
relações cidade- \\
campo que ocorreram \\
nos últimos trinta \\
anos. \\
\end{tabular} & \begin{tabular}{|c|} 
Chácara, Coronel \\
Pacheco, Olaria, \\
Santa Maria do \\
M. Verde, Água \\
Comprida, \\
Comendador \\
Gomes, Pirajuba \\
e Veríssimo - \\
MG (menos de 3 \\
mil hab.) \\
\end{tabular} & $\begin{array}{l}\text { Relação cidade-campo } \\
\text { funções urbanas e } \\
\text { relações econômicas. }\end{array}$ \\
\hline $\begin{array}{l}\text { Winston } \\
\text { Kleiber de } \\
\text { Almeida } \\
\text { BACELAR }\end{array}$ & $\begin{array}{c}\text { A Pequena Cidade } \\
\text { nas Teias da Aldeia } \\
\text { Global: as Relações e } \\
\text { Especificidades } \\
\text { Sociopolíticas nas } \\
\text { Pequenas Cidades de } \\
\text { Estrela do Sul, } \\
\text { Cascalho Rico e } \\
\text { Grupiara-MG }\end{array}$ & $\begin{array}{c}\text { Analisar a relação } \\
\text { entre o poder público } \\
\text { e a população de } \\
\text { cidades pequenas. }\end{array}$ & $\begin{array}{c}\text { Estrela do Sul, } \\
\text { Cascalho Rico e } \\
\text { Grupiara-MG } \\
\text { (menos de } 10 \text { mil } \\
\text { hab.) }\end{array}$ & $\begin{array}{c}\text { Contexto da } \\
\text { descentralização } \\
\text { administrativa; relaçõe } \\
\text { sociopolíticas; relação } \\
\text { entre poder público e a } \\
\text { população; atores } \\
\text { políticos; } \\
\text { sustentabilidade local; } \\
\text { o papel das festas e as } \\
\text { possibilidades de lazer }\end{array}$ \\
\hline $\begin{array}{l}\text { Hélcio } \\
\text { Ribeiro } \\
\text { CAMPOS }\end{array}$ & \begin{tabular}{|c} 
Transformações \\
urbanas recentes em \\
Tiradentes-MG: anos \\
80 e 90 do século XX
\end{tabular} & $\begin{array}{c}\text { Identificar as } \\
\text { transformações } \\
\text { recentes ocorridas no } \\
\text { espaço urbano de } \\
\text { Tiradentes, } \\
\text { protagonizada pelo } \\
\text { centro histórico e } \\
\text { pela periferia, } \\
\text { marcada pela abertura } \\
\text { de loteamentos nas } \\
\text { últimas décadas. }\end{array}$ & $\begin{array}{c}\text { Tiradentes - MG } \\
\text { (menos de } 10 \text { mil } \\
\text { hab.) }\end{array}$ & \begin{tabular}{|c} 
O uso, a ocupação e a \\
valorização imobiliária \\
migração; leitura de \\
uma cidade histórica e \\
turística; \\
transformações \\
socioeconômicas e \\
espaciais; restauração, \\
revitalização e \\
gentrificação.
\end{tabular} \\
\hline
\end{tabular}




\begin{tabular}{|c|c|c|c|c|}
\hline $\begin{array}{l}\text { Severina Sarah } \\
\text { LISBOA }\end{array}$ & $\begin{array}{l}\text { Da migração à } \\
\text { não migração: o } \\
\text { exemplo de } \\
\text { pequenas } \\
\text { cidades da zona } \\
\text { da mata mineira }\end{array}$ & \begin{tabular}{|} 
Identificar e analisar os \\
fatores determinantes \\
da migração e da não \\
migração na área de \\
estudo.
\end{tabular} & \begin{tabular}{|c|} 
Ervália, \\
Piranga e \\
Teixeiras - \\
MG \\
(menos de 20 \\
mil hab.)
\end{tabular} & $\begin{array}{l}\text { Dinâmica demográfica; } \\
\text { fatores econômicos e } \\
\text { culturais; causas } \\
\text { determinantes dos } \\
\text { deslocamentos } \\
\text { migratórios; fatores } \\
\text { objetivos e subjetivos } \\
\text { que influem na migração } \\
\text { ou na não migração. }\end{array}$ \\
\hline $\begin{array}{c}\text { Mariana } \\
\text { Alvarenga do } \\
\text { NASCIMENTO }\end{array}$ & \begin{tabular}{|} 
Planejamento \\
ambiental para \\
cidades \\
pequenas: o caso \\
de Perdões - \\
MG \\
\end{tabular} & \begin{tabular}{|c|} 
Demonstrar que o \\
planejamento ambiental \\
também é importante \\
para as cidades \\
pequenas
\end{tabular} & $\begin{array}{c}\text { Perdões - MG } \\
\text { (menos de } 20 \\
\text { mil hab.) }\end{array}$ & $\begin{array}{l}\text { Papel desempenhado } \\
\text { pela cidade na rede } \\
\text { urbana; sociedade e } \\
\text { meio ambiente; relação } \\
\text { global e local; análise da } \\
\text { sustentabilidade. }\end{array}$ \\
\hline $\begin{array}{l}\text { Anete M. } \\
\text { PEREIRA }\end{array}$ & $\begin{array}{l}\text { Cidade Média e } \\
\text { Região: o } \\
\text { significado de } \\
\text { Montes Claros } \\
\text { no Norte de } \\
\text { Minas Gerais }\end{array}$ & \begin{tabular}{|c|} 
Compreender a \\
dinâmica, as funções e \\
os fluxos que definem o \\
papel regional de \\
Montes Claros e a \\
configuração de uma \\
rede urbana regional.
\end{tabular} & $\begin{array}{l}\text { Região norte } \\
\text { mineira } \\
\text { (menos de } 20 \\
\text { mil hab.) }\end{array}$ & $\begin{array}{l}\text { Rede urbana; relações } \\
\text { urbano-regionais }\end{array}$ \\
\hline $\begin{array}{l}\text { Márcio M. } \\
\text { MACHADO }\end{array}$ & $\begin{array}{c}\text { Sistemas de } \\
\text { informações } \\
\text { geográficas para } \\
\text { auxiliar no } \\
\text { desenvolvimento } \\
\text { local, endógeno } \\
\text { e sustentável de } \\
\text { municípios de } \\
\text { pequeno porte: o } \\
\text { caso de } \\
\text { Jaboticatubas }\end{array}$ & \begin{tabular}{|} 
Analisar a viabilidade \\
de se implementar \\
àquela ferramenta de \\
geoprocessamento, \\
associada ao de Sistema \\
de Posicionamento \\
Global - GPS para \\
auxiliar a sociedade \\
local na representação \\
da sustentabilidade de \\
seus recursos naturais e \\
culturais.
\end{tabular} & $\begin{array}{l}\text { Jaboticatubas - } \\
\text { MG } \\
\text { (menos de } 20 \\
\text { mil hab.) }\end{array}$ & $\begin{array}{c}\text { Desenvolvimento } \\
\text { socioeconômico } \\
\text { sustentável; emprego de } \\
\text { tecnologia de } \\
\text { geoprocessamento. }\end{array}$ \\
\hline
\end{tabular}




\begin{tabular}{|c|c|c|c|c|}
\hline $\begin{array}{l}\text { Viviane dos G. } \\
\text { Alvim NUNES }\end{array}$ & $\begin{array}{l}\text { Plano Diretor: } \\
\text { uma } \\
\text { metodologia de } \\
\text { elaboração para } \\
\text { municípios de } \\
\text { pequeno porte }\end{array}$ & \begin{tabular}{|c|} 
Propor uma \\
metodologia para a \\
elaboração de Planos \\
Diretores voltados aos \\
pequenos municípios, \\
adequada à sua \\
realidade e contexto e \\
de acordo com o \\
Estatuto da Cidade, que \\
prevê a gestão \\
participativa como \\
condição essencial.
\end{tabular} & $\begin{array}{l}\text { Tupaciguara - } \\
\text { MG } \\
\text { (menos de } 25 \\
\text { mil hab.) }\end{array}$ & $\begin{array}{c}\text { Análise de planos } \\
\text { diretores; análise de } \\
\text { metodologias e das } \\
\text { características de } \\
\text { pequenos municípios; } \\
\text { análise da gestão urbana. }\end{array}$ \\
\hline $\begin{array}{l}\text { Alessandra R. } \\
\text { FERREIRA }\end{array}$ & $\begin{array}{l}\text { Tupaciguara 'Lá } \\
\text { Tem': } \\
\text { revitalização } \\
\text { urbana e cultura } \\
\text { popular }\end{array}$ & \begin{tabular}{|c|} 
Apresentar uma \\
reflexão sobre a \\
importância do aspecto \\
cultural na cidade de \\
pequeno porte, \\
considerando a cultura \\
imaterial existente no \\
município de \\
Tupaciguara. \\
\end{tabular} & $\begin{array}{l}\text { Tupaciguara - } \\
\text { MG } \\
\text { (menos de } 25 \\
\text { mil hab.) }\end{array}$ & $\begin{array}{c}\text { Leitura cultural; } \\
\text { identidade da população; } \\
\text { valores e costumes; } \\
\text { práticas culturais } \\
\text { populares; análise do } \\
\text { Plano Diretor. }\end{array}$ \\
\hline $\begin{array}{c}\text { Nádia C. da Silva } \\
\text { MELLO }\end{array}$ & $\begin{array}{l}\text { A cidade local } \\
\text { no contexto da } \\
\text { globalização: o } \\
\text { exemplo de } \\
\text { Machado/MG }\end{array}$ & \begin{tabular}{|} 
Compreender a relação \\
entre as transformações \\
socioespaciais refletidas \\
no processo de \\
urbanização, diante do \\
processo de \\
globalização.
\end{tabular} & $\begin{array}{l}\text { Machado- } \\
\text { MG } \\
\text { (menos de } 50 \\
\text { mil hab.) }\end{array}$ & $\begin{array}{l}\text { Relação entre o global e } \\
\text { o local; transformações } \\
\text { socioespaciais; aspectos } \\
\text { econômicos. }\end{array}$ \\
\hline $\begin{array}{l}\text { Edson Soares } \\
\text { FIALHO }\end{array}$ & $\begin{array}{l}\text { Ilha de calor em } \\
\text { cidade de } \\
\text { pequeno porte: } \\
\text { caso de Viçosa }\end{array}$ & $\begin{array}{c}\text { Procurou investigar a } \\
\text { hipótese da constituição } \\
\text { de um clima urbano } \\
\text { associado ao } \\
\text { crescimento da cidade } \\
\text { sede do município de } \\
\text { Viçosa. }\end{array}$ & $\begin{array}{l}\text { Viçosa-MG } \\
\text { (menos de } 75 \\
\text { mil hab.) }\end{array}$ & $\begin{array}{l}\text { Ilhas de calor; técnicas } \\
\text { próprias da climatologia. }\end{array}$ \\
\hline $\begin{array}{c}\text { Paula Savegnago } \\
\text { ROSSATO }\end{array}$ & \begin{tabular}{|c|} 
O sistema \\
termodinâmico \\
do clima urbano \\
de Nova Palma, \\
RS: contribuição \\
ao clima urbano \\
de cidades \\
pequenas
\end{tabular} & \begin{tabular}{|} 
Estudar o clima urbano \\
em cidades pequenas, a \\
fim de diagnosticar e \\
prevenir os possíveis \\
problemas que as \\
mesmas possam vir a \\
enfrentar futuramente \\
ao se tornarem cidades \\
de porte maior.
\end{tabular} & $\begin{array}{l}\text { Nova Palma - } \\
\text { RS } \\
\text { (menos de } 10 \\
\text { mil hab.) }\end{array}$ & $\begin{array}{c}\text { Características espaciais } \\
\text { do espaço urbano; } \\
\text { técnicas próprias da } \\
\text { climatologia. }\end{array}$ \\
\hline
\end{tabular}




\begin{tabular}{|c|c|c|c|c|}
\hline $\begin{array}{c}\text { Vilma D. M. } \\
\text { FIGUEIREDO }\end{array}$ & \begin{tabular}{|c|} 
Pequenos \\
municípios e \\
pequenas \\
cidades do \\
estado do Rio \\
Grande do Sul: \\
contrastes, perfil \\
do \\
desenvolvimento \\
e da qualidade \\
de vida, $1980-$ \\
2000
\end{tabular} & $\begin{array}{l}\text { Avaliar municípios do } \\
\text { estado do Rio Grande } \\
\text { do Sul, estando a } \\
\text { questão fundamental } \\
\text { voltada para a avaliação } \\
\text { de seus papéis no } \\
\text { contexto do } \\
\text { desenvolvimento } \\
\text { estadual, com ênfase } \\
\text { nos aspectos } \\
\text { relacionados à } \\
\text { qualidade de vida. }\end{array}$ & $\begin{array}{l}\text { Nova Araçá, } \\
\text { Chiapeta, } \\
\text { Mariano } \\
\text { Moro, Paraí, } \\
\text { Selbach, } \\
\text { Braga, } \\
\text { Cambará Sul, } \\
\text { Campinas Sul, } \\
\text { Formigueiro, } \\
\text { Herval, } \\
\text { Humaitá, } \\
\text { Lavras do Sul, } \\
\text { Miraguaí, } \\
\text { Roca Sales e } \\
\text { Santana da } \\
\text { Boa Vista - } \\
\text { RS } \\
\text { (menos de } 10 \\
\text { mil hab.) } \\
\end{array}$ & $\begin{array}{l}\text { Dinâmica demográfica; } \\
\text { transformações } \\
\text { econômicas, sociais e } \\
\text { políticas; indicadores de } \\
\text { qualidade de vida e de } \\
\text { desenvolvimento } \\
\text { econômico. }\end{array}$ \\
\hline $\begin{array}{c}\text { Silvane } \\
\text { SPOLAOR }\end{array}$ & $\begin{array}{c}\text { Os papéis } \\
\text { urbanos nas } \\
\text { pequenas } \\
\text { cidades da } \\
\text { região da Quarta } \\
\text { Colônia - RS }\end{array}$ & $\begin{array}{c}\text { Identificar os papéis } \\
\text { urbanos das pequenas } \\
\text { cidades que fazem parte } \\
\text { da região da Quarta } \\
\text { Colônia, a composição } \\
\text { do espaço urbano dos } \\
\text { seus municípios, } \\
\text { analisando suas } \\
\text { relações com o espaço } \\
\text { regional. }\end{array}$ & $\begin{array}{l}\text { Agudo, Dona } \\
\text { Francisca, } \\
\text { Faxinal do } \\
\text { Soturno, Ivorá, } \\
\text { Nova Palma, } \\
\text { Pinhal Grande, } \\
\text { Restinga Seca, } \\
\text { São João do } \\
\text { Polêsine e } \\
\text { Silveira } \\
\text { Martins - RS } \\
\text { (menos de } 20 \\
\text { mil hab.) }\end{array}$ & $\begin{array}{l}\text { Análise regional; relação } \\
\text { campo-cidade; papéis } \\
\text { urbanos no contexto } \\
\text { regional. }\end{array}$ \\
\hline $\begin{array}{c}\text { Fabiano Bolzan } \\
\text { SCHERER }\end{array}$ & $\begin{array}{l}\text { Construção do } \\
\text { espaço urbano } \\
\text { da pequena } \\
\text { cidade: um } \\
\text { estudo sobre São } \\
\text { Sepé - RS }\end{array}$ & $\begin{array}{l}\text { Analisa em suas escalas } \\
\text { espaciais e temporais os } \\
\text { papéis e o uso do solo } \\
\text { urbano da pequena } \\
\text { cidade de São Sepé, } \\
\text { cujas dinâmicas } \\
\text { atrelam-se ao setor } \\
\text { agropecuário no qual a } \\
\text { cidade está envolvida. }\end{array}$ & $\begin{array}{c}\text { São Sepé - RS } \\
\text { (menos de } 25 \\
\text { mil hab.) }\end{array}$ & $\begin{array}{l}\text { Papéis econômicos; } \\
\text { equipamentos e } \\
\text { infraestrutura urbana. }\end{array}$ \\
\hline
\end{tabular}




\begin{tabular}{|c|c|c|c|c|}
\hline $\begin{array}{c}\text { Erika } \\
\text { COLLISCHONN }\end{array}$ & $\begin{array}{l}\text { Inundações em } \\
\text { Venâncio } \\
\text { Aires/RS: } \\
\text { interações entre } \\
\text { as dinâmicas } \\
\text { natural e social } \\
\text { na formação de } \\
\text { riscos } \\
\text { socioambientais } \\
\text { urbanos }\end{array}$ & $\begin{array}{l}\text { Apreender os fatores } \\
\text { que contribuem na } \\
\text { construção do risco a } \\
\text { eventos pluviais } \\
\text { intensos numa cidade } \\
\text { de pequeno porte. }\end{array}$ & $\begin{array}{c}\text { Venâncio } \\
\text { Aires - RS } \\
\text { (menos de } 75 \\
\text { mil hab.) }\end{array}$ & $\begin{array}{l}\text { Espacialização- } \\
\text { periodização; mudanças } \\
\text { nas condições ecológicas } \\
\text { associadas ao tamanho } \\
\text { demográfico; dinâmica } \\
\text { natural e dinâmica } \\
\text { social. }\end{array}$ \\
\hline $\begin{array}{l}\text { Sérgio H. R. } \\
\text { CRIVELARO }\end{array}$ & $\begin{array}{l}\text { Espaço vivido, } \\
\text { cotidiano e } \\
\text { qualidade de } \\
\text { vida em } \\
\text { pequenos } \\
\text { municípios. } \\
\text { Caso: município } \\
\text { de Urupês (SP) }\end{array}$ & $\begin{array}{c}\text { Compreender as } \\
\text { práticas cotidianas dos } \\
\text { moradores de pequenos } \\
\text { municípios em termos } \\
\text { socioespaciais, } \\
\text { ressaltando suas } \\
\text { relações de convívio e } \\
\text { sociabilidade, sua } \\
\text { percepção sobre } \\
\text { qualidade de vida e a } \\
\text { estruturação do espaço } \\
\text { vivido. }\end{array}$ & $\begin{array}{l}\text { Urupês - SP } \\
\text { (menos de } 20 \\
\text { mil hab.) }\end{array}$ & $\begin{array}{l}\text { Análise da qualidade de } \\
\text { vida; estudo do } \\
\text { cotidiano e do espaço } \\
\text { vivido; padrão } \\
\text { construtivo das casas. }\end{array}$ \\
\hline Érico SORIANO & $\begin{array}{l}\text { Os espaços de } \\
\text { medo e os de } \\
\text { castigo nas } \\
\text { pequenas } \\
\text { cidades do } \\
\text { estado de São } \\
\text { Paulo: o caso } \\
\text { Itirapina }\end{array}$ & $\begin{array}{l}\text { Contribuir para o } \\
\text { estudo da violência, da } \\
\text { criminalidade e do } \\
\text { medo em cidades } \\
\text { pequenas. Para tanto, } \\
\text { tem as unidades } \\
\text { prisionais como } \\
\text { elementos da paisagem } \\
\text { que contribuem para a } \\
\text { difusão da insegurança } \\
\text { e do medo. }\end{array}$ & $\begin{array}{l}\text { Itirapina - SP } \\
\text { (menos de } 20 \\
\text { mil hab.) }\end{array}$ & $\begin{array}{l}\text { Dinâmica demográfica; } \\
\text { relação entre o medo, o } \\
\text { crime e as unidades } \\
\text { prisionais. }\end{array}$ \\
\hline
\end{tabular}




\begin{tabular}{|c|c|c|c|c|}
\hline $\begin{array}{l}\text { Mara Lucia F. da } \\
\text { H. } \\
\text { BERNARDELLI }\end{array}$ & \begin{tabular}{|c|} 
Pequenas \\
cidades na \\
região de \\
Catanduva-SP: \\
papéis urbanos, \\
reprodução \\
social e \\
produção de \\
moradias
\end{tabular} & \begin{tabular}{|} 
Colaborar para a \\
reflexão das relações \\
entre o papel do poder \\
público, o processo de \\
produção da cidade e os \\
papéis urbanos; \\
analisando, \\
principalmente, a \\
territorialização das \\
políticas habitacionais \\
nas pequenas cidades \\
canavieiras da região de \\
Catanduva. \\
\end{tabular} & $\begin{array}{c}\text { Catiguá, } \\
\text { Ariranha, } \\
\text { Palmares } \\
\text { Paulista, } \\
\text { Pindorama e } \\
\text { Santa Adélia - } \\
\text { SP } \\
\text { (menos de } 20 \\
\text { mil hab.) }\end{array}$ & $\begin{array}{l}\text { Análise da rede urbana; } \\
\text { relação urbano-rural; } \\
\text { dinâmica populacional e } \\
\text { mercado de trabalho; } \\
\text { ramos de atividades } \\
\text { econômicas e atuação } \\
\text { dos agentes econômicos; } \\
\text { produção e condições de } \\
\text { moradia. }\end{array}$ \\
\hline $\begin{array}{c}\text { Cláudia Marques } \\
\text { ROMA }\end{array}$ & $\begin{array}{c}\text { Segregação } \\
\text { socioespacial em } \\
\text { cidades } \\
\text { pequenas }\end{array}$ & $\begin{array}{c}\text { Compreender as } \\
\text { dinâmicas segregativas } \\
\text { no contexto da } \\
\text { produção do espaço } \\
\text { urbano em cidades } \\
\text { pequenas. }\end{array}$ & $\begin{array}{l}\text { Mariápolis e } \\
\text { Osvaldo Cruz } \\
\text { - SP } \\
\text { (menos de } 50 \\
\text { mil hab.) }\end{array}$ & $\begin{array}{l}\text { Indicadores de condição } \\
\text { de vida urbana; } \\
\text { semelhanças e } \\
\text { diferenças nas } \\
\text { dimensões da } \\
\text { segregação } \\
\text { socioespacial; } \\
\text { segregação interurbana } \\
\text { (análise a partir da rede } \\
\text { urbana). } \\
\end{array}$ \\
\hline $\begin{array}{c}\text { Léia Aparecida } \\
\text { Veiga PINTO }\end{array}$ & \begin{tabular}{|c|} 
Jaguapitã - PR: \\
pequena cidade \\
da rede urbana \\
norte-paranaense \\
especializada na \\
produção \\
industrial de \\
mesas para \\
bilhar \\
\end{tabular} & $\begin{array}{c}\text { Compreender a } \\
\text { reinserção de Jaguapitã } \\
\text { - PR na rede urbana } \\
\text { norte-paranaense após a } \\
\text { década de } 1970 \text {, a partir } \\
\text { da especialização } \\
\text { produtiva em mesas } \\
\text { para bilhar. }\end{array}$ & $\begin{array}{l}\text { Jaguapitã - PR } \\
\text { (menos de } 15 \\
\text { mil hab.) }\end{array}$ & $\begin{array}{l}\text { Análise histórica; rede } \\
\text { urbana; especialização } \\
\text { produtiva. }\end{array}$ \\
\hline $\begin{array}{l}\text { Sueli Aparecida } \\
\text { LOPES }\end{array}$ & $\begin{array}{l}\text { Autoconstrução } \\
\text { em Sertanópolis: } \\
\text { resolução do } \\
\text { problema da } \\
\text { moradia ou } \\
\text { exaustão da } \\
\text { força de } \\
\text { trabalho? }\end{array}$ & $\begin{array}{l}\text { Analisar os processos } \\
\text { que envolvem a } \\
\text { autoconstrução numa } \\
\text { cidade pequena. }\end{array}$ & $\begin{array}{l}\text { Sertanópolis - } \\
\text { PR } \\
\text { (menos de } 20 \\
\text { mil hab.) }\end{array}$ & $\begin{array}{l}\text { Aspectos da } \\
\text { autoconstrução; o papel } \\
\text { do poder público; } \\
\text { produção e condição de } \\
\text { moradia. }\end{array}$ \\
\hline
\end{tabular}




\begin{tabular}{|c|c|c|c|c|}
\hline $\begin{array}{l}\text { Angela Maria } \\
\text { ENDLICH }\end{array}$ & \begin{tabular}{|c|} 
Pensando os \\
papéis e \\
significados das \\
pequenas \\
cidades do \\
noroeste do \\
Paraná
\end{tabular} & $\begin{array}{l}\text { Estudar as cidades } \\
\text { pequenas num novo } \\
\text { contexto econômico, } \\
\text { seus papéis, } \\
\text { possibilidades e } \\
\text { significados. }\end{array}$ & $\begin{array}{c}\text { Colorado, } \\
\text { Querência do } \\
\text { Norte, Rondon } \\
\text { e Terra Rica - } \\
\text { PR } \\
\text { (menos de } 25 \\
\text { mil hab.) }\end{array}$ & $\begin{array}{l}\text { Análise da rede urbana; } \\
\text { papéis e significados das } \\
\text { pequenas cidades; } \\
\text { dinâmica demográfica e } \\
\text { mercado de trabalho; } \\
\text { relação local e global; } \\
\text { condições materiais e } \\
\text { especificidades políticas }\end{array}$ \\
\hline $\begin{array}{c}\text { Tatiane } \\
\text { SAFFNAUER }\end{array}$ & $\begin{array}{l}\text { A (Re) Produção } \\
\text { do espaço } \\
\text { urbano de Dois } \\
\text { Vizinhos no } \\
\text { contexto do } \\
\text { Sudoeste } \\
\text { paranaense }\end{array}$ & $\begin{array}{l}\text { Analisar as ações das } \\
\text { esferas pública e } \\
\text { privada que } \\
\text { objetivavam a } \\
\text { reprodução do capital, o } \\
\text { que se refletiu nas } \\
\text { diferentes formas de } \\
\text { consumo da cidade. }\end{array}$ & $\begin{array}{c}\text { Dois Vizinhos } \\
- \text { PR } \\
\text { (menos de } 50 \\
\text { mil hab.) }\end{array}$ & $\begin{array}{c}\text { Espaço urbano como } \\
\text { categoria de análise; } \\
\text { papel do Estado; atuação } \\
\text { da esfera privada. }\end{array}$ \\
\hline $\begin{array}{c}\text { Francisco } \\
\text { Ednardo } \\
\text { GONÇALVES }\end{array}$ & $\begin{array}{c}\text { Cidades } \\
\text { Pequenas, } \\
\text { Grandes } \\
\text { Problemas: } \\
\text { Perfil Urbano do } \\
\text { Agreste Potiguar }\end{array}$ & $\begin{array}{c}\text { Apreender a } \\
\text { configuração } \\
\text { socioespacial do urbano } \\
\text { e analisar o perfil } \\
\text { urbano das cidades } \\
\text { pequenas do Agreste } \\
\text { Potiguar. }\end{array}$ & \begin{tabular}{|c|} 
Bom Jesus, \\
Ielmo \\
Marinho, \\
Januário \\
Cicco, Lagoa \\
d'Anta, Lagoa \\
de Pedras, \\
Lagoa \\
Salgada, \\
Monte Alegre, \\
Nova Cruz, \\
Passa e Fica, \\
Passagem, \\
Presidente \\
Juscelino, \\
Riachuelo, \\
Santa Maria, \\
Santo Antônio, \\
São Paulo do \\
Potengi, São \\
Pedro, \\
Senador Elói \\
de Souza, \\
Sorrinha, \\
Várzea e Vera \\
Cruz- RN \\
(menos de 50 \\
mil hab.) \\
\end{tabular} & $\begin{array}{l}\text { Análise urbana e } \\
\text { regional; dinâmica } \\
\text { demográfica; } \\
\text { características } \\
\text { econômicas; indicadores } \\
\text { sociais; especificidades } \\
\text { locais. }\end{array}$ \\
\hline
\end{tabular}




\begin{tabular}{|c|c|c|c|c|}
\hline $\begin{array}{l}\text { Maria Suely da } \\
\text { Silva } \\
\text { MEDEIROS }\end{array}$ & $\begin{array}{l}\text { A produção do } \\
\text { espaço das } \\
\text { pequenas } \\
\text { cidades do } \\
\text { Seridó Potiguar }\end{array}$ & $\begin{array}{c}\text { Compreender o } \\
\text { processo de produção } \\
\text { do espaço das pequenas } \\
\text { cidades situadas no } \\
\text { Seridó Potiguar, sob } \\
\text { uma perspectiva } \\
\text { histórica. }\end{array}$ & \begin{tabular}{|} 
Santana do \\
Seridó, São \\
Fernando, \\
Ipueira, \\
Timbaúba dos \\
Batistas, São \\
José do Seridó, \\
Serra Negra do \\
Norte, Ouro \\
Branco, São \\
João do \\
Sabugi, \\
Equador, \\
Carnaúba dos \\
Dantas, \\
Cruzeta, Acari, \\
Jardim de \\
Piranhas, \\
Jardim do \\
Seridó, \\
Parelhas - RN \\
(menos de 20 \\
mil hab.)
\end{tabular} & $\begin{array}{l}\text { Análise dos serviços } \\
\text { públicos; análise do } \\
\text { comércio e serviços; a } \\
\text { construção da } \\
\text { identidade. }\end{array}$ \\
\hline $\begin{array}{c}\text { Márcia Silva de } \\
\text { MEDEIROS }\end{array}$ & $\begin{array}{l}\text { Na Esquina do } \\
\text { Brasil: uma } \\
\text { leitura } \\
\text { geográfica da } \\
\text { (re)construção } \\
\text { do território }\end{array}$ & $\begin{array}{l}\text { Identificar o processo } \\
\text { de (re)construção do } \\
\text { território da pequena } \\
\text { cidade de Touros - RN. }\end{array}$ & $\begin{array}{c}\text { Touros - RN } \\
\text { (menos de } 50 \\
\text { mil hab.) }\end{array}$ & $\begin{array}{l}\text { Análise socioespacial; } \\
\text { construção de } \\
\text { territorialidades urbanas. }\end{array}$ \\
\hline $\begin{array}{l}\text { Nágela } \\
\text { Aparecida de } \\
\text { MELO }\end{array}$ & $\begin{array}{c}\text { Pequenas } \\
\text { cidades da } \\
\text { microrregião } \\
\text { geográfica de } \\
\text { Catalão (GO): } \\
\text { análises de seus } \\
\text { conteúdos e } \\
\text { considerações } \\
\text { teórico- } \\
\text { metodológicas }\end{array}$ & $\begin{array}{c}\text { Compreender a } \\
\text { formação espacial, as } \\
\text { funções, as dinâmicas e } \\
\text { os significados } \\
\text { socioeconômicos e } \\
\text { espaciais das pequenas } \\
\text { cidades da microrregião } \\
\text { geográfica de Catalão. }\end{array}$ & $\begin{array}{l}\text { Anhanguera, } \\
\text { Campo Alegre } \\
\text { de Goiás, } \\
\text { Corumbaíba, } \\
\text { Cumari, } \\
\text { Davinópolis, } \\
\text { Goiandira, } \\
\text { Ipameri, Nova } \\
\text { Aurora, } \\
\text { Ouvidor e Três } \\
\text { Ranchos - GO } \\
\text { (menos de } 25 \\
\text { mil hab.) }\end{array}$ & $\begin{array}{l}\text { Formação socioespacial; } \\
\text { dinâmica territorial; } \\
\text { aspectos econômicos; } \\
\text { organização espacial das } \\
\text { cidades pequenas; } \\
\text { equipamentos e } \\
\text { infraestruturas urbanas; } \\
\text { dinâmica populacional, } \\
\text { envelhecimento e } \\
\text { emprego. }\end{array}$ \\
\hline
\end{tabular}




\begin{tabular}{|c|c|c|c|c|}
\hline $\begin{array}{c}\text { Elson Rodrigues } \\
\text { OLANDA }\end{array}$ & \begin{tabular}{|} 
Sanclerlândia - \\
GO: do povoado \\
do Cruzeiro às \\
novas \\
centralidades
\end{tabular} & $\begin{array}{c}\text { Compreender a } \\
\text { constituição e a } \\
\text { ampliação das } \\
\text { centralidades intra e } \\
\text { interurbana na e da } \\
\text { cidade. }\end{array}$ & $\begin{array}{l}\text { Sanclerlândia } \\
- \text { GO } \\
\text { (menos de } 10 \\
\text { mil hab.) }\end{array}$ & $\begin{array}{c}\text { Análise histórica de } \\
\text { formação territorial; } \\
\text { análise da centralidade; } \\
\text { relações interurbanas. }\end{array}$ \\
\hline $\begin{array}{l}\text { Maria Alice } \\
\text { Alkmim } \\
\text { ANDRADE }\end{array}$ & $\begin{array}{l}\text { Transformações } \\
\text { em Curso no } \\
\text { Perfil } \\
\text { Econômico e } \\
\text { Sócioespacial de } \\
\text { Cidades de } \\
\text { Pequeno Porte: o } \\
\text { Exemplo de } \\
\text { Bom Jesus de } \\
\text { Itabapoana no } \\
\text { Noroeste } \\
\text { Fluminense } \\
\end{array}$ & $\begin{array}{c}\text { Identificar as } \\
\text { transformações em } \\
\text { curso no perfil } \\
\text { econômico e espacial } \\
\text { da cidade estudada. }\end{array}$ & $\begin{array}{l}\text { Bom Jesus de } \\
\text { Itabapoana - } \\
\text { RJ } \\
\text { (menos de } 50 \\
\text { mil hab.) }\end{array}$ & $\begin{array}{l}\text { Relações socioespaciais; } \\
\text { gestão urbana e atores } \\
\text { sociais; contexto da } \\
\text { descentralização } \\
\text { administrativa; } \\
\text { organização espacial; } \\
\text { perfil econômico. }\end{array}$ \\
\hline $\begin{array}{c}\text { L. M. V. } \\
\text { BELTRÃO }\end{array}$ & \begin{tabular}{|c|} 
A \\
industrialização \\
em Sombrio: \\
gênese e \\
evolução
\end{tabular} & \begin{tabular}{|c|} 
Demonstrar as \\
condições para a gênese \\
do processo industrial e \\
a evolução de cada um \\
dos ramos industriais \\
principais, tanto no que \\
se refere ao movimento \\
econômico como às \\
suas vinculações \\
espaciais externas.
\end{tabular} & $\begin{array}{c}\text { Sombrio - SC } \\
\text { (menos de } 30 \\
\text { mil hab.) }\end{array}$ & $\begin{array}{c}\text { Análise da } \\
\text { industrialização; } \\
\text { externalidades; } \\
\text { estruturação do espaço a } \\
\text { partir da atividade } \\
\text { econômica. }\end{array}$ \\
\hline $\begin{array}{c}\text { Diva Maria } \\
\text { Ferlin LOPES }\end{array}$ & $\begin{array}{l}\text { O conceito de } \\
\text { urbano e as } \\
\text { cidades de } \\
\text { pequeno porte } \\
\text { no semiárido } \\
\text { baiano: Novo } \\
\text { Triunfo, Santa } \\
\text { Brígida e Sítio } \\
\text { do Quinto } \\
\end{array}$ & $\begin{array}{l}\text { Identificar a existência } \\
\text { ou não de } \\
\text { características urbanas } \\
\text { nas cidades estudadas. }\end{array}$ & $\begin{array}{c}\text { Novo Triunfo, } \\
\text { Santa Brígida } \\
\text { e Sítio do } \\
\text { Quinto - BA } \\
\text { (menos de } 20 \\
\text { mil hab.) }\end{array}$ & $\begin{array}{l}\text { Número de habitantes; } \\
\text { centralidade econômica; } \\
\text { multiplicidade de uso do } \\
\text { solo; diversidade } \\
\text { econômica; presença de } \\
\text { classes sociais distintas; } \\
\text { proporção de residentes } \\
\text { ocupados em atividades } \\
\text { não agrícolas. }\end{array}$ \\
\hline $\begin{array}{l}\text { Rita de Cássia } \\
\text { Gregório de } \\
\text { ANDRADE }\end{array}$ & $\begin{array}{l}\text { A Cidade de } \\
\text { Coremas - PB: } \\
\text { Geografia } \\
\text { Histórica de uma } \\
\text { Pequena Cidade }\end{array}$ & $\begin{array}{l}\text { Analisar os processos } \\
\text { históricos, econômicos } \\
\text { e políticos que levaram } \\
\text { ao surgimento da } \\
\text { cidade de Coremas. }\end{array}$ & $\begin{array}{c}\text { Coremas - PB } \\
\text { (menos de } 20 \\
\text { mil hab.) }\end{array}$ & $\begin{array}{l}\text { Análise documental; } \\
\text { análise histórica; } \\
\text { transformações do } \\
\text { espaço urbano. }\end{array}$ \\
\hline
\end{tabular}


Fonte: Elaborado a partir da análise das Teses e Dissertações dos Programas de PósGraduação em Geografia, por Orlando Moreira Junior, 2014.

Data de submissão19/09/2013

Data de aprovação: 18/09/2014 